IMF TECHNICAL NOTES AND MANUALS

\title{
Tax Administration:
} Designing a Business Continuity Plan for an Epidemic

John Brondolo, Joshua Aslett, and Andja Komso

Fiscal Affairs Department

I NTERNATIONAL MONETARY FUND 


\section{INTERNATIONAL MONETARY FUND}

Fiscal Affairs Department

Tax Administration:

Designing a Business Continuity Plan for an Epidemic

Prepared by John Brondolo, Joshua Aslett, and Andja Komso ${ }^{1}$

Authorized for distribution by Michael Keen

October 2020

DISCLAIMER: This Technical Guidance Note should not be reported as

representing the views of the IMF. The views expressed in this paper are

those of the authors and do not necessarily represent the views of the IMF,

its Executive Board, or IMF management

\begin{tabular}{|ll|}
\hline JEL Classification Numbers: & $\mathrm{H} 2, \mathrm{H} 2 \mathrm{O}, \mathrm{H} 83, \mathrm{H} 120$ \\
\hline Keywords: & Tax administration; business continuity plan; crisis management \\
\hline Authors' E-Mail Addresses: & $\begin{array}{l}\text { jbrondolo@IMF.org } \\
\text { jaslett@gmail.com } \\
\\
\text { akomso@IMF.org }\end{array}$ \\
\hline
\end{tabular}

1 This note has benefited from guidance and comments provided by Brendan Jones and Matthew Coffey (Australian Tax Office), Torsten Jacobsen (Danish Tax Administration), Vanessa Johnson, Elizabeth Sartorelli and Margaret Thomson (Inland Revenue New Zealand), Datuk Nizom, Marhaini Mahmood, and Rasyidah Che Rosli (Inland Revenue Board of Malaysia), Thomas Brandt (Internal Revenue Service of the United States), Batjargal Zayabal and Mr Damdinpurev Tsogtjargal (Mongolia Tax Administration), Pakun Tunmaneewattana (Thailand Revenue Department), and Debra Adams, Margaret Cotton, Michael Hardy, Michael Keen, Meg Klekner, Evelyn Nash, Paulo Paz, Enrique Rojas, and Rebecca Sparkman (International Monetary Fund). 


\title{
TECHNICAL NOTES AND MANUALS
}

\section{Tax Administration: Designing a Business} Continuity Plan for an Epidemic

\author{
Prepared by John Brondolo, Joshua Aslett, and Andja Komso
}

This technical note and manual (TNM) addresses the following questions:

- What is a business continuity plan (BCP) and what are its main components?

- What are a BCP's key design considerations for an epidemic?

- What are the organizational and management arrangements for a BCP?

- How does a BCP maintain a tax agency's critical functions during an epidemic?

- How does a tax agency keep its BCP current and ready for deployment? 


\section{CONTENTS}

I. Business Continuity Plan Defined. . $\ldots \ldots \ldots \ldots \ldots \ldots \ldots \ldots$

II. Key Considerations of a BCP for an Epidemic $\ldots \ldots \ldots \ldots \ldots \ldots \ldots \ldots$

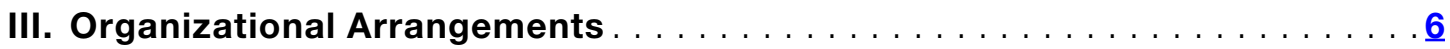

IV. Activation and Deployment $\ldots \ldots \ldots \ldots \ldots \ldots \ldots \ldots \ldots \ldots \ldots \ldots \ldots$

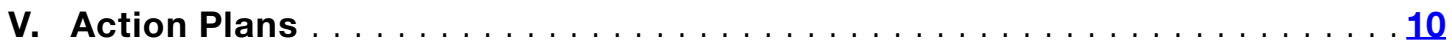

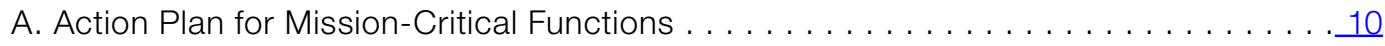

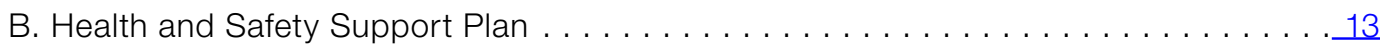

C. Workforce Deployment Support Plan . . . . . . . . . . . . . . . . . . 14

D. Information Technology Support Plan . . . . . . . . . . . . . . . . . . . . . . 15

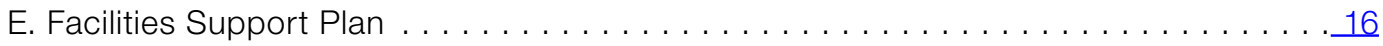

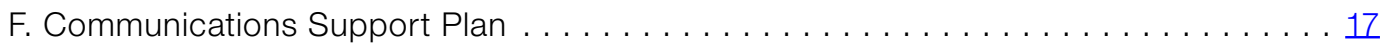

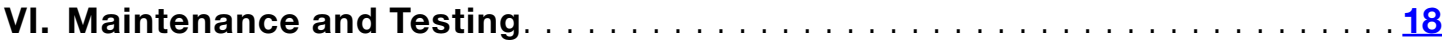

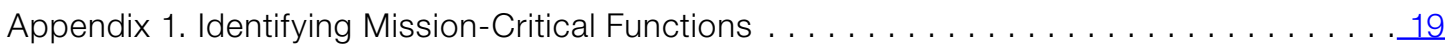

Appendix 2. Elements Of An Information Technology Support Plan. . . . . . . . . . . . 25 


\section{ACRONYMS}

\begin{tabular}{|c|c|}
\hline BCP. & Business Continuity Plan \\
\hline CMT. & Crisis Management Team \\
\hline COVID & Corona Virus Disease \\
\hline FAQ & Frequently Asked Questions \\
\hline GDP . & Gross Domestic Product \\
\hline IMF & International Monetary Fund \\
\hline IT . . & Information Technology \\
\hline MAO & Maximum Acceptable Outage \\
\hline MOF. & Ministry of Finance \\
\hline PC & Personal Computer \\
\hline RTO . & Recovery Time Objective \\
\hline TNM. & Technical Notes and Manuals \\
\hline VPN . & Virtual Private Network \\
\hline
\end{tabular}




\section{BUSINESS CONTINUITY PLAN DEFINED}

A business continuity plan (BCP) is an important planning tool that ensures continued tax administration operations in the event of major disruptions. Although the structure and contents of BCPs differ across tax administrations, many share the following components:

- A crisis management organization.

- A set of processes for identifying and escalating responses to crisis events.

- Action plans for preserving the tax administration's critical functions.

- Systems for maintaining the BCP's operational readiness when not in use.

The types of potential disruptions faced by tax administrations vary in complexity and severity. They include both internal disruptions (e.g., computer systems failure) and external (e.g., earthquakes, infectious disease). The disruptions may be localized (affecting one or a few tax offices) or national (affecting the tax administration's entire operations). The recent experience with the COVID-19 pandemic has shown that those tax agencies that have a documented BCP are better positioned to respond to a crisis than those that do not.

This note describes the key $\mathrm{BCP}$ design considerations for a severe infectious disease. Some aspects of the plan may be generally applicable to many types of disruptions. For example, the ability for staff to work remotely in an infectious disease scenario could be just as relevant in a case of an earthquake, fire, or flood. Nevertheless, the intent of this note is to inform planning discussions around the specific scenario of an epidemic (or pandemic), and not to provide a general-purpose continuity plan.

Tax agencies are strongly encouraged to invest the time and resources in designing a comprehensive BCP, taking into account the guidance provided in this note. Full-fledged business continuity plans may take time to develop and implement, but they bring the agency to a state of readiness that allows them to respond quickly and systematically to future emergency scenarios, while avoiding the need to depend on ad hoc responses. 


\section{KEY CONSIDERATIONS OF A BCP FOR AN EPIDEMIC}

\section{What is an epidemic and why is it important to plan for one?}

An epidemic is an infectious disease that affects a large number of people within a particular community. It can grow into a pandemic if the disease spreads over multiple countries. For ease of reference, epidemics and pandemics are collectively referred to in this document as an epidemic.

Evidence suggests that the likelihood of severe infectious disease events has increased in recent decades. The causes include increased global travel and integration, growing urbanization, changes in land use, and greater exploitation of the environment. These trends are likely to continue and intensify in the future. For this reason, governments around the world have given significant attention to mitigating the health and non-health impacts of infectious diseases, including safeguarding the delivery of essential government services such as tax administration.

Infectious diseases can have serious impacts on health outcomes. These impacts have been evidenced most recently by the COVID-19 pandemic which has, as of October 2020, resulted in over 35 million cases and more than 1 million deaths worldwide. Both morbidity and mortality tend to be higher in countries with weak or ineffective healthcare systems. An outbreak of a severe infectious disease can place new and sustained levels of stress on already fragile services.

Infectious diseases also have the potential to cause serious economic damage. As an example, the IMF has projected global growth at -4.9 percent, 1.9 percentage points below its April 2020 forecast at the outset of the pandemic. ${ }^{2}$ In 2021 global growth is projected at 5.4 percent. Overall, this would leave 2021 GDP some 6 $\frac{1}{2}$ percentage points lower than in the pre-COVID-19 projections of January 2020. The adverse impact on low-income households is particularly acute, imperiling the significant progress made in reducing extreme poverty in the world since the 1990s.

\section{What are some of the important challenges to consider?}

An epidemic may have pervasive implications for tax administration that rapidly materialize and evolve, including:

- Disruption of normal social and business functions, including closures of businesses, schools, and other institutions.

- Significant reductions in the number of tax administration staff available for work due to illness or other factors related to an outbreak.

- A requirement for some or all of the tax administration's functions to be performed remotely (i.e., at an alternate workplace, including from home).

- Changes in tax and social policy, requiring new tax administration procedures, staffing, training and enhancements to information systems.

- The potential for crisis conditions to persist for at least 1 month, with the possibility of subsequent infection waves. 


\section{What are the typical objectives of a BCP for a severe infectious disease?}

To formulate productive objectives, tax administrations need to consider their holistic, unique context. Because an epidemic's effects are widespread, both internal priorities and external factors should factor into the analysis. This includes examination of relevant national policies, requirements and BCPs of key partners (e.g., Ministry of Finance, banking system, service providers), unique mandates (e.g., administration of social benefits) and the realistic potential for any substantive policy changes. Accordingly, BCP's for an epidemic are often designed around the following key objectives:

- Maintain the operation of the tax administration's most critical operational and support functions at an acceptable performance level.

- Protect the health and safety of tax administration staff and visitors.

- Enable the temporary replacement of tax administration management and staff in the event that they are unavailable or otherwise incapable of performing their duties.

- Protect the tax administration's essential facilities, records, and other assets.

- Contribute to whole-of-government responses to an epvidemic.

\section{ORGANIZATIONAL ARRANGEMENTS}

A typical organizational structure for administering a BCP is depicted in Box 1. As illustrated, it is comprised of a Commissioner, Crisis Management Team (CMT), local implementation teams, and the internal audit unit. This structure is defined in the BCP itself and made operational upon $\mathrm{BCP}$ activation, most often in response to a crisis. The CMT should have the authority to act and make decisions on crisis-related issues on behalf of the tax administration. Depending on a country's legal practices, the authorities may be stipulated in legislation, administrative orders, or other legal instruments.

In larger tax administrations, having more resources, dedicated business continuity management teams may already exist. These teams are typically established on a permanent basis to assist an activated Crisis Management Team in triaging incidents and deploying business continuity action plans. They provide additional support throughout a crisis by assisting in postcrisis debriefings, testing exercises, updating and maintaining BCP components. 
BOX 1. Crisis Management Organization Framework

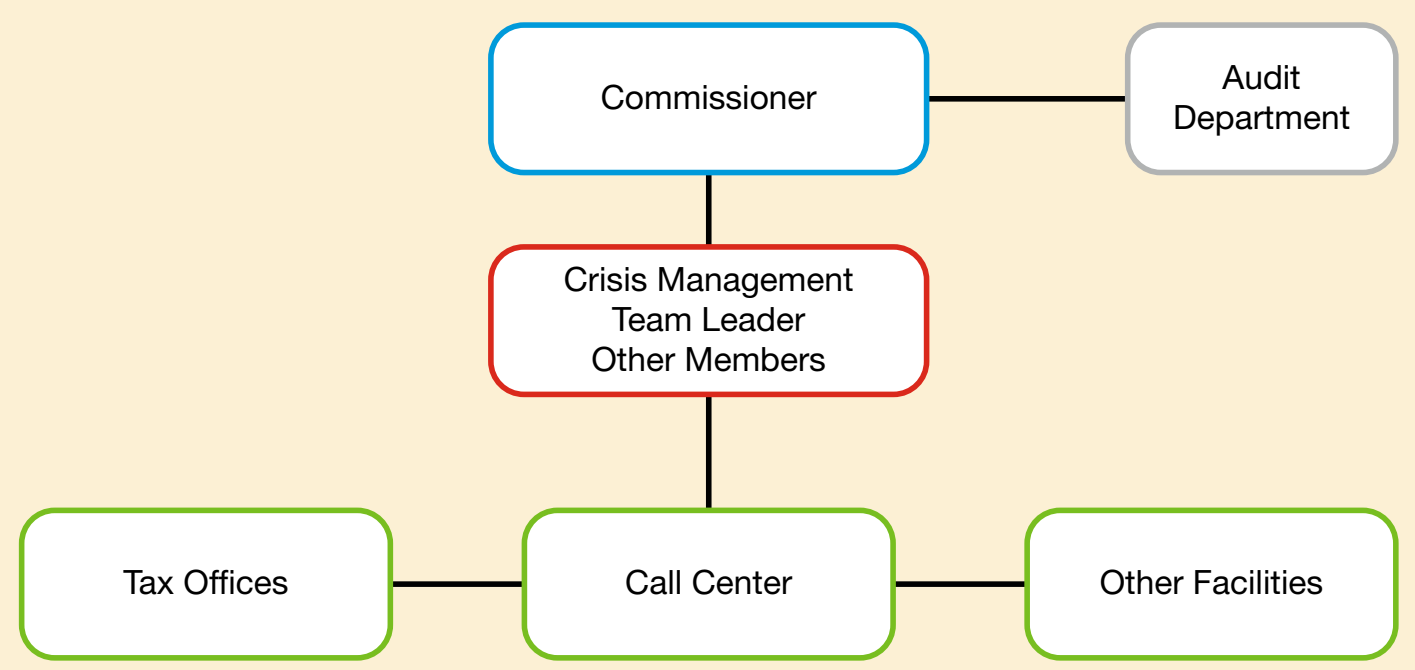

The Commissioner approves the BCP and ensures its operational readiness, including by securing adequate budget resources, conducting maintenance, testing activities, and certifying annual audits.

The Crisis Management Team comprises a leader, deputy leader, several members, and a secretariat. In some tax agencies, the CMT will include all department heads in the interest of keeping the agency's entire top management informed of the CMT's operations. Other tax agencies restrict CMT membership to only those department directors who have a role in implementing specific elements of the BCP. This is intended to keep the CMT manageable and focused. A reasonable compromise would be to restrict the team's full-time members but invite other officials to attend the meetings when needed. All team members should be responsible for designating an alternate member.

Tax Offices, Call Center, and Other Facilities implement and monitor business continuity action plans in their jurisdictions. Some tax agencies create special implementation teams while others rely on the existing local management to implement the BCP.

Internal Audit conducts regular audits of the BCP, including evaluating the respective organization and management arrangements, action plans, budget arrangements, maintenance and testing practices. It would also play a key role in conducting postdeployment reviews of BCP, particularly in accounting for the budgetary resources used during the crisis. Audit results are reported to the Commissioner. 


\section{ACTIVATION AND DEPLOYMENT}

A formalized and systematic process for activating the crisis management team and deploying the $\mathrm{BCP}$ is crucial to managing a disruptive event. In many tax administrations this is achieved by utilizing a triage matrix to classify incidents (including those involving an epidemic) and determine how they are to be managed. A typical scheme classifies incidents into one of four levels: ${ }^{3}$

- Level 0. Sudden, passing events. Minimal potential to impact business lines or tax offices. Requires little coordination. For an infectious disease, this level could correspond to a significant increase in seasonal viruses at one location within the country.

- Level 1. Shorter duration events. Impacts limited number of business lines and few tax offices. Requires some coordination. For infectious diseases, this could involve a significant increase in seasonal viruses in a few locations.

- Level 2. Extended duration events. Impacts multiple business lines and tax offices. Requires wide coordination at senior levels. For an infectious disease, this level could correspond to a significant increase in seasonal viruses on a national scale or the initial outbreak of a novel virus in one or a few locations.

- Level 3. Extended duration events. Major impact on a tax agency's critical functions. Requires whole-of-tax agency and / or whole-of-government coordination. For an infectious disease, this could involve a national outbreak of a novel virus.

The severity of incidents, along with their patterns and potential impacts, can prompt an escalated response - which may include BCP deployment. As an example, sudden Level 0 incidents, which involve minor disruptions, would normally be addressed through standard operational procedures and managed at the local level. Higher Level 1-3 incidents, on the other hand, may require the activation of a crisis management team whose leadership and membership will vary depending on severity, from a deputy commissioner to a department director or other senior staff.

An epidemic will almost always lead to the direct engagement of top management and BCP deployment. The typical sequence of events and responsibilities for identifying the crisis, notifying senior staff, activating the crisis management team, and deploying the business continuity plan are summarized Figure 1.

Once activated, the BCP's Crisis Management Team assumes command and control responsibilities throughout the crisis. It reviews the BCP's contingency action plans (described in Section V) prior to their deployment, decides whether any adjustments are required, and issues instructions for their implementation. After the BCP has been deployed, the CMT will monitor its implementation, identify and take decisions on emerging issues, maintain communications with staff and external stakeholders, and ultimately decide when to return to business as usual. 
FIGURE 1. BCP Decision Points and CMT Responsibilities

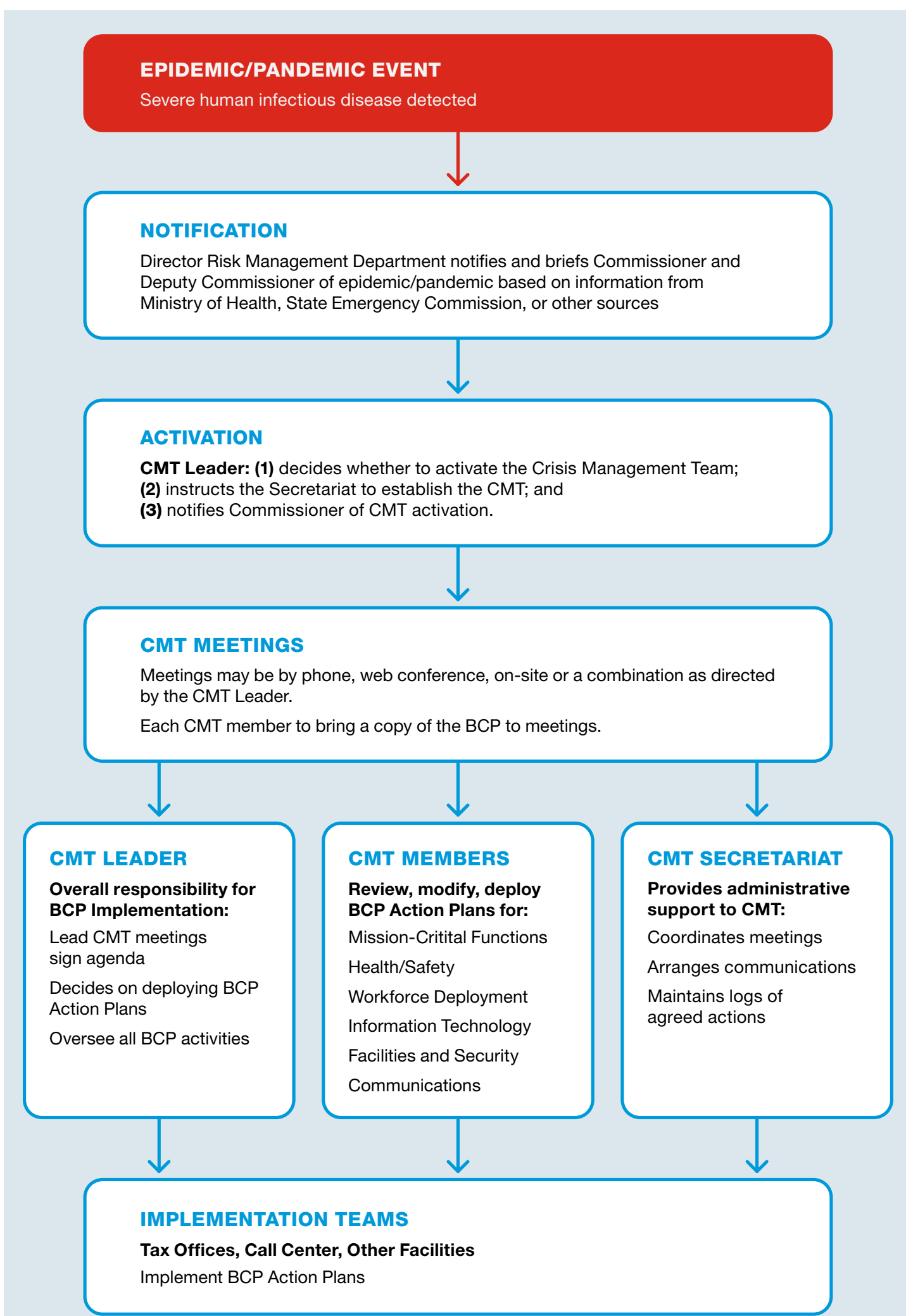




\section{ACTION PLANS}

A well-designed ВСР includes contingency action plans that are reviewed, approved and implemented by the CMT upon its activation. Their purpose is to provide assurance to the CMT and stakeholders - management, staff, the public, partners, and policymakers - that a crisis can be actively mitigated and managed. Contingency action plans are typically designed with considerable prior thought. In a crisis period with a short timeline to respond, this allows the CMT to prioritize implementation and action rather than open-ended research and deliberation.

Action plans for an epidemic scenario are typically developed for six areas:

- Mission-critical functions. Standalone action plans for each mission-critical function (e.g., filing, payment) identified from an objective analysis.

- Health and safety. A single action plan that incorporates national and international guidance, especially as it relates to infectious diseases.

- Workforce deployment. A single action plan describing transition of staff to a remote work configuration and between mission-critical functions.

- Information technology. A single action plan that ensures uninterrupted availability of core processing systems and electronic taxpayer services.

- Facilities. A single action plan that facilitates secure closing, reopening, and limited access to a tax administration's network of offices.

- Communications. A single action plan specifying the channels, authorities and processes for both internal and external communication during the crisis.

To be effective, sufficient time and resources need to be invested in preparing action plans in advance and at a sufficient level of detail. In tax administrations with strong management and governance processes, action plans may require only broad statements of intent. In others, and for a variety of reasons, action plans should be prescriptive and explicitly describe exact steps to be taken by staff. The decision over what level of detail to target is best made through internal consultations and validation of the $\mathrm{BCP}$ action plans through regular testing.

The following guidance and illustrative examples address each of the six action plan topics. The content is tailored specifically to an epidemic scenario. It is intended to provide input into broader planning discussions and not a "copy / paste", one-size-fits-all solution.

\section{A. Action Plan for Mission-Critical Functions}

These plans are designed to ensure that a tax agency can continue performing its most important operations throughout a crisis. They address all phases of the potential crisis and are commonly developed using the following four steps:

- Step 1. Identify the tax agency's full set of functions and work processes.

- Step 2. Rank the functions and processes according to their criticality.

- Step 3. Identify vulnerabilities of the most critical functions and processes based on the specific scenario that the BCP will address (including an epidemic).

- Step 4. Reengineer the functions and processes so that they can continue to be performed effectively until the disruption has abated. 


\section{Step 1: Identify a tax agency's functions and work processes}

The effort required for this first step depends on whether functions and processes have been documented. Some tax agencies will maintain a complete set of documentation which greatly facilitates the analysis. More commonly, the documentation is either incomplete or does not exist. In such cases, two alternative approaches could be considered: (1) prepare a comprehensive list of functions / processes based on international practices and identify those that are relevant to the tax agency or (2) arrange for each department to produce a list of its functions / processes and cross-check the results against a list of international practices.

\section{Step 2: Rank functions and processes}

The next step is to analyzes and assess the functions and processes according to their degree of criticality. This is typically achieved by applying a standardized set of criteria to the list of functions/processes and ranking each from least critical to most critical. An example of such a methodology is provided in Appendix 1. In doing so, some tax agencies find it useful to classify their most important functions and processes into two categories: (1) mission-critical functions and (2) essential support functions.

Mission-Critical Functions are those activities that directly relate to accomplishing the tax administration's mission of collecting and accounting for tax revenue. The failure of a missioncritical function would have an immediate, negative, and serious impact on tax revenues, taxpayers and/or tax administration staff.

Essential Support Functions must be performed to achieve the tax administration's missioncritical functions. These are facilitative activities. They are important and urgent but accomplishing them does not deliver on the core tax administration mission.

Examples of mission-critical and essential support functions are listed in Table 1. All other tax administration functions and processes are typically considered to be non-critical for the purposes of a business continuity plan for an epidemic. While important to maintaining an efficient and effective tax administration, they are not considered to be an immediate priority. The tax agency can address their performance outside of the business continuity plan or defer them until after the epidemic has abated. For example, although auditing is not typically considered mission-critical, the tax administration should continue to give appropriate attention during an epidemic to auditing large taxpayers and companies achieving windfall gains as well prosecuting tax crimes

\section{TABLE 1. Examples of Mission-Critical and Essential Support Functions}

\begin{tabular}{|ll|}
\hline \multicolumn{1}{|c|}{ MISSION-CRITICAL FUNCTIONS } & ESSENTIAL SUPPORT FUNCTIONS \\
\hline Registration & Human Resources \\
\hline Tax Declaration Filing and Processing & Information Systems, Internet, Email \\
\hline Tax Payment and Processing & Office Facilities \\
\hline Tax Accounting & Call Center \\
\hline Refunds & Data Exchange \\
\hline
\end{tabular}




\section{Steps 3 and 4: Determine vulnerabilities and design treatments}

After identifying critical functions, the final steps are to perform a targeted risk analysis and develop the actual action plans. This is achieved by first (1) determining those critical functions that are vulnerable to major disruption during an epidemic and then (2) redesigning (or strengthening) them so that they can continue to be performed at an acceptable level until the epidemic has ended. ${ }^{4}$ The specific activities, projects and other interventions necessary to maintain the function form the basis of its action plan.

Common tax administration vulnerabilities to an epidemic and their potential solutions are presented in Table 2. The relevance of the insights in Table 2 will vary considerably across tax administrations based on how respective functions are performed and local conditions. Regardless, they may provide a basis for planning risk analysis and should be considered when developing BCP action plans.

\section{TABLE 2. Continuity Vulnerabilities and Treatments}

\section{VULNERABILITIES}

Physical presence dependency

Some key functions and processes must be conducted at tax offices, which would not be possible if the offices were closed due to an epidemic.

\section{Paper-based operations}

Some key functions/processes are either fully or partially paper-based. The delivery, receipt, and processing of such documents would be vulnerable to disruption by an epidemic.

\section{Workforce vulnerabilities}

Key functions would be disrupted if significant numbers of staff assigned to these functions were unavailable to work because of epidemic-induced illness or risk of illness.

\section{Information systems vulnerabilities}

Key functions would be disrupted if the tax administration's computer systems fail for any reasons, which may include insufficient capacity to handle increased demand for online services during an epidemic.

\section{Dependency on external organizations}

Some partner organizations may not have a workable BCP putting at risk their capacity to provide services exchange critically needed information during a crisis. These organizations could include, for example, commercial banks, MOF Treasury, registration agencies, customs department, and important vendors and suppliers.

\section{TREATMENTS}

Reengineer the functions and processes so that they may be performed remotely or otherwise avoid the need for face-to-face interactions. For example, enhance e-tax services, create drop-boxes for submitting tax returns, increase call center resources, or temporarily suspend face-to-face verification activities until the epidemic abates.

Reengineer the functions and processes to enable fully paperless operation. For example, allow taxpayers to submit a scan or photo of a registration application tax returns and/or other documents via email.

Prepare a workforce redeployment plan that identifies options for (temporarily) replacing mission-critical and key support staff. For example, cancel leave plans, approve overtime or hire temporary staff, and reallocate non-critical staff to mission-critical functions.

Confirm disaster recovery plans, database failover ${ }^{5}$ procedures, telecommunications failover configuration, capacity to scale-up IT capacity to meet demand increase, and backup/recovery procedures. Also ensure tax agency maintains manual (non-digital) processing capabilities.

Encourage partner organizations to develop a BCP that is compatible with the tax administration's BCP, implement redundant connectivity with partner organizations, and establish two working-level points of contact between each partner organization and at least one tax administration IT staff member.

5 Failover technique is a method of protecting computer systems from failure in which standby equipment automatically takes over when the main system fails. 


\section{B. Health and Safety Support Plan}

The BCP should place a high priority on protecting all staff and visitors from infectious disease. This can be achieved by designing a health and safety support plan that includes a graduated sets of health responses aligned to the phases of the epidemic. The phases and responses are normally developed in close consultation with the country's health authorities and conform with government-wide policies in this area. A high-level plan with 3 phases and illustrative responses is set out in Table 3 .

\section{TABLE 3. Epidemic Levels and Graduated Responses}

\section{PHASE ALERT LEVEL HEALTH INDICATORS HEALTH RESPONSES}

1 Pre-Outbreak Normal number of seasonal infectious disease cases.

No cases of novel infectious disease reported.
Maintain staff awareness of seasonal infectious diseases, their symptoms and effects, and types of preventions. In addition:

- Replenish health supplies at the minimum stock level.

- Prepare a list of medical supplies distributors and arrange servicelevel agreements.

\section{Outbreak}

Epidemic Alert
Significant Increase in the number of seasonal infectious disease cases; and/or,

Some cases of novel infectious disease identified in the country.
Create enhanced staff awareness of seasonal and novel infectious diseases:

- Provide additional information on tax agency intranet and social media.

- Implement social distancing and temperature scanning practices.

- Intensify cleaning/disinfecting offices.

- Determine additional medical supplies needed, secure budgetary funds, activate accelerated procurement.

- Initiate quarantine procedures.

- Report infected staff to health ministry.

Create highest staff awareness by continuing Phase 2 responses and: infectious diseases among the general population; and/or,

Clusters of novel infectious disease reported among general population
- Create hotline and direct emails with updates on the infectious disease.

- Provide staff with safety kit.

- Allow remote work for selected staff and/or permit office staff to work in shifts.

- Consider closing tax offices 
The graduated health responses referred to in Table 3 should be underpinned by policies and procedures governing:

- Medical supplies and equipment. The requirements and procedures for procuring and distributing health-related supplies and equipment at different stages of an infection event.

- Infection reporting. The requirement for staff members who have been tested positive for the epidemic and/or exhibit symptoms to complete an on-line report that includes information on their last day in the office before diagnosis, tax office locations visited and persons with whom the employee had close contact in the 48 hours prior to diagnosis.

- High Risk and Mission Critical Staff. The procedures for identifying and requiring remote work for those staff who are highly vulnerable to severe infectious disease or mission-critical without replacement.

- Isolation and Quarantining. The obligations and procedures by which tax administration staff who are suspected or have been confirmed to be infected will be isolated (in the office) and eventually quarantined (outside the office).

\section{Workforce Deployment Support Plan}

A central theme of BCPs designed for epidemics is to ensure the tax administration has an adequate workforce to perform its critical functions. This requires careful advanced planning to determine: (1) acceptable levels of performance for each critical function; (2) the potential for temporary or permanent reassignment of staff between functions; and (3) the ability of staff to deliver the work required from alternate duty stations, which may include remotely from home. The requisite prior planning allows a CMT to quickly formulate and execute a concise workforce redeployment plan when needed.

\section{Key elements of a workforce redeployment plan include:}

- Identification of minimal staffing levels and contingencies if staffing falls below those levels. For each critical function, the tax agency' should identify their current staffing numbers, the minimum number of staff require to perform their mission-critical functions at an acceptable level, and a plan for temporarily filling workforce gaps. The latter may include staff reassignments, cancellation of holidays and leave, overtime, or use of temporary workers, contractors, and other service providers.

- Development and maintenance of a workforce roster. Specifying the departments (and positions) that each staff member can be temporarily reassigned to as needed.

- Provisions for cross-training of staff between functions. To include a potential need for training to be delivered remotely in an electronic format.

- Rules of succession if key staff become unavailable due to illness. Ensuring continued delivery of services through delegation of authorities. The rules should be based on position or title (rather than name) and stipulate the conditions under which succession will take place and the method of notification. Although the rules are typically codified outside the BCP (e.g., civil service law, tax administration act, internal tax administration orders), they should also be referenced in the $\mathrm{BCP}$ 
As a precondition for remote work, staff agreement to a remote work policy should be a non-negotiable requirement. The primary intent of such policies is to ensure that staff remain productive working remotely while maintaining a high level of accountability and integrity. This includes a need to protect government assets, most importantly the confidentiality of sensitive taxpayer information. Typical elements of remote work policies for tax administration include:

- A mandate to report time and maintain communications with managers and co-workers. Facilitated by online time reporting systems, case management systems, and virtual meetings tools.

- Consent to monitoring by management, internal audit, and IT personnel. Informing staff that they are being actively monitored and should have no expectation of privacy when using government-issued equipment.

- Protect all government records and data against unauthorized disclosure and access. Requiring compliance with security measures including computer cable locks, multifactor authentication and data (and device) encryption.

- Use of government equipment for official business only. Explicitly prohibiting use of government devices by family members or friends, or for entertainment purposes (i.e., downloading movies, playing video games etc.).

- Notification of penalties and sanctions for breach of the policy. Specifying the relevant legislation and potential criminal or civil actions that will be taken.

\section{Information Technology Support Plan}

In a BCP designed to mitigate an epidemic, information technology support is of paramount importance. At a minimum, the respective support plan must ensure the uninterrupted availability of: (1) core processing systems; (2) electronic taxpayer services; and (3) IT elements of mission-critical and essential support functions. This includes enabling designated staff to work remotely by providing the necessary equipment, training, and secure electronic access to systems. Examples of these actions are summarized below with details provided in Appendix 2:

- Maintain Essential Support Functions. Implement enhanced measures that guarantee the secure availability of identified essential support functions. Report planned, anticipated or actual service disruptions to the CMT Leader without delay.

- Confirm Emergency Procedures and Core Operations. Ensure that approved emergency IT procedures, failover techniques, and backups for core IT operations are in-place and configured for an epidemic scenario. Analyze critical procedures, infrastructure, systems, and support services to ensure their viability in a remote work configuration. Identify single points of failure and initiate emergency procurements.

- Deploy Remote Work Capabilities. Lead the deployment of the devices and electronic services required to provide secure work-from-home capabilities for staff. Regularly report progress to the CMT Team Leader, noting potential obstacles.

- Redeploy IT Staff and Confirm Assignments. Direct most IT staff to transition into a remote configuration while ensuring that responsibilities for core IT operations are clear. Ensure sufficient resources to support the broader remote workforce transition.

- Deliver Priority Systems Development. Establish a team to implement reengineered business processes and policy measures. Relax change controls for low-risk interventions. Reconcile BCP action plan requirements with current conditions. 
- Secure Information and Assets in Closing Facilities. Manage the shutdown, storage and security of devices and information during the crisis period, accounting for both end-user and backoffice assets.

\section{E. Facilities Support Plan}

Planning is also needed to ensure the safety and integrity of a tax administration's facilities during an epidemic. Those facilities that remain open must provide a safe working environment for staff and visitors while those that are closed must be maintained and secured for the duration of the shutdown. A facilities support plan can help in this regard by providing a set of protocols for safely operating open facilities and orderly decommissioning those to be closed (and, eventually, reopened after the epidemic has abated).

The Crisis Management Team should recommend to the Commissioner facilities that are to be closed or remain open during (or reopen after) the epidemic. Considerations could include government-wide policies, national and local travel restrictions, stay-at-home orders, and rates of employee absenteeism due to an epidemic. Protocols for facilities that will remain open (or reopen) and those that will be temporarily closed are listed in Box 2 . The protocols should be reviewed as the epidemic unfolds to take account of changing conditions

\section{BOX 2. Protocols for Opening/Reopening and Closing Facilities}

\section{Open/Reopened Facilities}

$\checkmark$ Implement restrictions for staff and visitor access, including temperature scanning, social distancing, use of disinfecting hand washes, and mandatory wearing of masks.

$\checkmark$ Maintain a list of visitors to each facility that can be used to support contact tracing.

$\checkmark$ Print and post signage at entrances and general use areas on social distancing, mask wearing, hand washing, and other practices.

$\checkmark$ Acquire and distribute equipment, including masks, gloves, sanitizers,

$\checkmark$ Implement enhanced infrastructure controls, including protective barriers and air filtering systems.

$\checkmark$ Intensify cleaning procedures.

$\checkmark$ Reassign/reconfigure workspaces and common areas for social distancing.

$\checkmark$ Determine the procedures to safely return staff to pre-crisis operations (including those listed above).

$\checkmark$ Ensure staff returning to the office are informed of new safety responsibilities.

\section{Closed Facilities}

$\checkmark$ Decommission and maintain physical infrastructure and equipment.

$\checkmark$ Put in place appropriate security arrangements, in coordination with local police, maintain security systems, conduct regular security tours.

$\checkmark$ Issue instructions for staff to safeguard all sensitive information and documents.

$\checkmark$ Perform a full inventory of computer equipment, fully shutdown all PCs and wireless transmission devices, shutdown other IT equipment based on explicit instruction from the IT department.

$\checkmark$ Remove trash and arrange cleaning at reduced service levels.

$\checkmark$ Cancel or reschedule deliveries or services. 


\section{F. Communications Support Plan}

Effective communications underpin a tax administration's response to a crisis and are an integral part of BCP development. A communications support plan is intended to convey the relevant information to the right people in a timely manner and through the best channel. For each targeted audience, the plan contains details of (1) how information is to be delivered to the target groups and (2) the person or team responsible for drafting, approving, and delivering the messages. This concept is typically tailored and applied for planning both internal and external communications strategies.

\section{Internal Communications}

The CMT is typically tasked with ensuring that managers and staff are kept up to date on the epidemic. Some tax agencies will provide managers with summaries of CMT meetings and information packages containing the key information to be provided to staff, including answers to anticipated staff questions. Staff are usually provided information on health and safety issues, changes in work procedures, human resource management policies (including leave and remote work policies), and other issues relevant to the crisis. Common internal communications channels include:

\footnotetext{
$\checkmark$ Posting statements and frequently asked questions (FAQs) on an Intranet.

$\checkmark$ Sending emails or SMS messages directly to employees.

$\checkmark$ Establishing a telephone number with recorded information that employees can call.

$\checkmark$ Setting up an email account for employees to direct questions to.
}

\section{External Communications}

The communications plan will also keep external stakeholders informed of implications of the crisis and response measures. Stakeholders include key government leaders and agencies, taxpayers and tax return preparers, industry and service associations, banks, suppliers and key service providers. Messages may be delivered via private meetings, press conferences, sending communications to the press / media, posting information on the tax administration's external website, and posting updates on social media. The content, timing and distribution of critical messages are to be agreed by the CMT Leader, often in consultation with the Commissioner. 


\section{MAINTENANCE AND TESTING}

The BCP should be endorsed and approved by the Commissioner. In addition, an appropriately senior official should be assigned responsibility for maintaining the plan, which should be stored in a central repository that can be easily accessed during an emergency

To ensure its viability and effectiveness, there is an ongoing requirement to maintain the BCP and test its implementation. This is typically achieved by establishing procedures for staff to conduct periodic reviews and simulations.

At a minimum, the BCP should be reviewed and amended annually. The review is intended to produce both substantive and administrative updates. Substantive updates include such matters as identifying changes to mission-critical and essential support functions (by reapplying the methodology described in Appendix 1) as well as revising action and support plans to include new treatments for vulnerable functions and processes. Administrative updates will involve accounting for organizational and staff changes such as updating the names and contact information for CMT members.

A regular exercise should also be scheduled to establish and confirm confidence in the BCP's operational readiness. The testing exercise is typically included in annual work plans. It is usually based on a realistic scenario that is well-planned with clearly defined purposes and objectives. Careful planning is often taken to ensure that the exercise does not disrupt actual operations. Upon its completion, a formal post-exercise report is usually produced along with outcomes and recommendations. This document is usually reviewed by senior management and follow-up action taken to make the required adjustments. 


\section{APPENDIX 1. IDENTIFYING MISSION-CRITICAL FUNCTIONS}

This appendix presents a methodology for identifying a tax administration's most important ("mission-critical") functions. This task is integral to designing a business continuity plan whose central purpose is to ensure that the mission-critical functions continue to operate at an acceptable performance level during a major disruptive event (e.g., an earthquake, fire, flood, pandemic or other major disruptions). The general approach to identifying mission-critical functions is summarized in Figure 2 and elaborated below.

FIGURE 2. Key Steps in Identifying Mission-Critical Functions

\begin{tabular}{|c|c|c|c|c|}
\hline $\begin{array}{l}\text { Prepare a } \\
\text { comprehensive } \\
\text { list of funcitions } \\
\text { and work } \\
\text { processes }\end{array}$ & $\begin{array}{l}\text { Select an } \\
\text { approach } \\
\text { for identifying } \\
\text { mission-critical } \\
\text { functions }\end{array}$ & $\begin{array}{l}\text { Select criteria } \\
\text { for evaluating } \\
\text { the functions } \\
\text { and/or work } \\
\text { processes }\end{array}$ & $\begin{array}{l}\text { Applying the } \\
\text { criteria to the } \\
\text { functions } \\
\text { and/or work } \\
\text { processes }\end{array}$ & $\begin{array}{l}\text { Perform a } \\
\text { detailed analysis } \\
\text { of the work } \\
\text { processes for } \\
\text { mission-critical } \\
\text { functions }\end{array}$ \\
\hline $\begin{array}{l}\text { - Operational } \\
\text { function } \\
\text { - Supporting } \\
\text { functions }\end{array}$ & $\begin{array}{l}\text { - Top-down } \\
\text { - Bottom-up }\end{array}$ & $\begin{array}{l}\text { - Tax revenue } \\
\text { - Taxpayers } \\
\text { - Staff }\end{array}$ & $\begin{array}{l}\text { - Preliminary list of } \\
\text { mission-critical } \\
\text { functions } \\
\text { - Final list of } \\
\text { mission critical } \\
\text { functions }\end{array}$ & $\begin{array}{l}\text { - Determine the } \\
\text { impact on work } \\
\text { process outage } \\
\text { - Determine } \\
\text { priority list of } \\
\text { processes for } \\
\text { their restoration }\end{array}$ \\
\hline
\end{tabular}

\section{Step 1. Prepare a comprehensive list of functions and work processes.}

The functions represent a tax administration's main activities such as registration, returns processing, tax payment processing, audit, information technology, and human resources. Work processes are tasks that comprise the functions. For example, work processes for the registration function include submission of a registration application, review of applications, proof of identity, issuance of a certificate, etc.

For analytical purposes, it is often useful to categorize the functions and their underlying work processes into two groups: operational (e.g., registration, tax returns filing and processing, audit, etc.) and support (e.g., human resources, information systems, finance). This provides a deeper understanding of the role that each function plays and the impact(s) that its disruption would have on the tax administration's performance.

\section{Step 2. Select a "top-down" or "bottom-up" approach for identifying mission-critical functions.}

Under a "top-down" approach, each tax administration function (e.g., registration, tax returns, tax payments, human resources, information technology) will be evaluated without regard to its underlying work processes. Subsequently, the work processes will be subject to a more detailed analysis but only for those functions that have been identified previously as mission-critical. 
An alternate approach is to infer the mission-critical functions from an analysis of the functions' underlying work processes. Under this "bottom-up" approach, a function would be considered mission-critical if the any of its underlying processes are assessed to be mission-critical.

The decision on which approach to adopt involves a trade-off between ease of application and analytical rigor. The top-down approach has the advantage of simplicity and quick application since there are far fewer functions to evaluate (normally less than 30 ) than work processes (which may exceed 300-400). But by excluding work processes from the analysis, the top-down approach runs the risk that a function may have been mistakenly evaluated as non-critical when a more rigorous analysis of its underlying work processes would have revealed that some of the processes (and, hence, the function) are indeed mission-critical.

Based on the above considerations, a strong argument can be made in favor of the bottom-up approach because its analytical rigor is likely to produce more accurate and defensible results. This argument, of course, depends on whether the tax administration has the time and information required to identify and evaluate its many processes.

\section{Step 3. Select criteria for evaluating the functions and/or work processes.}

The criteria are intended to identify mission-critical functions by assessing the impact that a function's disruption would have on the tax administration's performance. Those functions with the biggest impacts (as determined by applying either the top-down or bottom-up approach) would be considered to be mission-critical.

A broad range of criteria could be used to assess the impacts of a function's disruption, including its impacts on the tax administration's key outputs (i.e., the amount of revenue collected, the processing of tax returns, the issuance of refund), reputation among stakeholders, and compliance with legislative requirements.

A number of considerations should be taken into account in selecting the criteria. To keep the analysis manageable, it is preferable to use no more than three-five criteria. In addition, the criteria should reflect a balanced set of perspectives, including those of tax administration, taxpayers, and tax administration staff. Further, criteria that can be quantified are preferred over those that rely on subjective judgment since the former is more likely to facilitate an objective and consistent analysis. Based on these considerations, a representative set of criteria for evaluating each function could include:

- Tax revenue impact: the estimated amount of tax revenue deferred or lost as a percentage of the annual revenue target (or forecast) resulting from a one-month disruption in its availability.

- Taxpayer impact: the estimated percentage of staff that normally use the function/process and would be affected by a one-month disruption in its availability.

- Tax administration staff impact: the percentage of staff that normally use the work process and would be affected by a one-month disruption in its availability. 


\section{Step 4. Apply the criteria to the functions and/or the work processes.}

This is facilitated by an assessment matrix like the one presented in Table 4. For each criterion, the impact of a one-month disruption to a function (using the top-down approach) or work process (using the bottom-up approach) can be rated at five levels of severity (extreme, major, moderate, minor, and none). The impact ratings can then be mapped to different levels of criticality (mission-critical, important, non-critical) to identify the mission-critical functions as shown in the last column of the table.

\section{TABLE 4. Mission-Criticality Assessment Matrix}

\begin{tabular}{|c|c|c|c|c|}
\hline \multirow{2}{*}{$\begin{array}{l}\text { IMPACT } \\
\text { RATING }\end{array}$} & \multicolumn{3}{|c|}{$\begin{array}{c}\text { Impact of a failure to perform a function/process } \\
\text { for one month or more }\end{array}$} & \multirow{2}{*}{$\begin{array}{l}\text { CRITICALITY } \\
\text { RATING }\end{array}$} \\
\hline & $\begin{array}{l}\text { Tax Revenue } \\
\text { Impact }\end{array}$ & $\begin{array}{c}\text { Taxpayers' } \\
\text { Impact }\end{array}$ & $\begin{array}{l}\text { Staff } \\
\text { Impact }\end{array}$ & \\
\hline 1. Extreme & More than $10 \%$ & More than $30 \%$ & More than $30 \%$ & Mission-Critical \\
\hline 2. Major & $5-10 \%$ & $20-30 \%$ & $20-30 \%$ & Mission-Critical \\
\hline 3. Moderate & $1-4 \%$ & $10-20 \%$ & $10-20 \%$ & Important \\
\hline 4. Minor & Less than $1 \%$ & Less than $10 \%$ & Less than $10 \%$ & Non-Critical \\
\hline 5. None & No revenue loss & $\begin{array}{l}\text { No taxpayers } \\
\text { are affected }\end{array}$ & $\begin{array}{l}\text { No staff } \\
\text { are affected }\end{array}$ & Non-Critical \\
\hline
\end{tabular}

In applying the assessment matrix under the top-down approach, a function would be considered mission-critical if the impact from its disruption is rated as either "major" or "severe" for any of the assessment criteria. Under the bottom-up approach, a function would be considered missioncritical if the impact from a disruption to any of its underlying processes is rated as "major" or "severe" for any of the criteria.

Typically, the above analysis is carried out in two stages. First, a preliminary list of missioncritical functions is prepared based on a "mechanical" application of the criteria. In the second stage, the preliminary list is reviewed and validated by the tax administration's senior management to identify any anomalies in the results. This will result in a final list of mission-critical functions by removing from the preliminary list those functions that do not warrant inclusion and adding others that may have been omitted 


\section{Step 5. Perform a detailed analysis of the of the work processes.}

This analysis is performed only on those work processes associated with a mission-critical function as identified in earlier steps. The results from this exercise helps to inform the business continuity plan by establishing priorities among the various processes.

The importance of each work process is determined by calculating its Maximum Acceptable Outage (the MAO). The MAO indicates the point (measured in days or weeks) at which the disruption of a work process would cause an "unacceptable" impact. This is determined by rating the impact that a work process's outage would have over time, typically in pre-selected intervals (e.g., 1-2 days, 3-5 days, 6-16 days, 16-30 days, $>30$ days).

Tables 5 and 6 provide two sets of criteria that can be used for this analysis. Table 5 assesses the MAO in terms of the impact that a work process's disruption would have on the performance of its associated function.

\section{TABLE 5. Work Process Impact Assessment: Function-Level}

\begin{tabular}{|c|c|c|}
\hline IMPACT LEVEL & ASSESSMENT & SCORE \\
\hline Extreme & The function will completely fail & 5 \\
\hline Major & Very high negative impact on delivering the function & 4 \\
\hline Moderate & Significant negative impact on delivering the function & 3 \\
\hline Minor & Minimal impact on delivering the function & 2 \\
\hline None & No impact on the function & 1 \\
\hline
\end{tabular}

Table 6 assesses the work processes in terms of their impact on higher-level objectives.

TABLE 6. Work Process Impact Assessment: High-Level Objectives

\begin{tabular}{|c|c|c|}
\hline IMPACT LEVEL & ASSESSMENT & SCORE \\
\hline Extreme & Threatens political and tax administration viability & 5 \\
\hline Major & Significant impact on core tax administration operations & 4 \\
\hline Moderate & Major impact on short-term tax administration operations & 3 \\
\hline Minor & Inconvenient but no substantive impact on operations & 2 \\
\hline None & No impact & 1 \\
\hline
\end{tabular}

Regardless of the assessment criteria selected, the MAO occurs at the point when the impact level reaches a rating of either "major" or "severe" (whichever occurs first). Prior to that point, the tax administration should implement the actions for assuring the work process' continuity as set out in the action plans described in Section IV.A. The end of this period is referred to as the Recovery Time Objective (RTO). For example, if a process' MAO occurs after 5 days of disruption then its RTO should be set at no later than the 4th day of the disruption. 
Establishing a system of meeting and exchanging ideas with external stakeholders can provide additional insights into factors driving compliance or creating noncompliance. Some examples of external stakeholders, who play a role in directly or indirectly supporting or governing HWIs in their financial affairs, are listed in Box 6. It may be difficult to open lines of communication initially with these stakeholders, but they can provide important insights on what is needed to enhance compliance. Meeting with these stakeholders on a periodic basis to discuss developments and compliance concerns can facilitate the design of the treatment strategy.

\section{Example}

Consider a scenario where after having completed steps 1-4, five mission-critical functions have been identified: registration, filing, payment, revenue accounting, and refunds. At that point, the tax administration would calculate the MAO and RTO for each of the function's underlying work processes as shown in Table 7 below. A MAO threshold will then be set (for example, 5 days) which will determine the priorities among the processes for assuring their continuity. In effect, this means that the action plans will allocate greater resources (staff, budget, IT) and effort to assuring those processes with ratings at or below the MAO. 
TABLE 7. Example-Determining the Maximum Acceptable Outage and the Recovery Time Objective

\begin{tabular}{|c|c|c|c|c|c|c|c|c|}
\hline \multirow{2}{*}{$\begin{array}{l}\text { IMPACT } \\
\text { LEVEL }\end{array}$} & \multirow[b]{2}{*}{ ASSESSMENT } & \multicolumn{5}{|c|}{ IMPACT SCORE } & \multirow[b]{2}{*}{ MAO } & \multirow[b]{2}{*}{ RTO } \\
\hline & & $\begin{array}{c}1-2 \\
\text { DAYS }\end{array}$ & $\begin{array}{c}3-5 \\
\text { DAYS }\end{array}$ & $\begin{array}{c}6-15 \\
\text { DAYS }\end{array}$ & $\begin{array}{l}16-30 \\
\text { DAYS }\end{array}$ & $\begin{array}{l}>30 \\
\text { DAYS }\end{array}$ & & \\
\hline \multirow{5}{*}{ Registration } & $\begin{array}{l}\text { 1. Submission of } \\
\text { registration application }\end{array}$ & 3 & 4 & 4 & 5 & 5 & 3 days & 2 days \\
\hline & 2. Registration data entry & 1 & 3 & 4 & 5 & 5 & 6 days & 5 days \\
\hline & 3. Review/validate registration data & 1 & 1 & 2 & 3 & 4 & 31 days & 30 days \\
\hline & 4. Proof of identity & 1 & 1 & 2 & 3 & 4 & 31 days & 30 days \\
\hline & 5. Issuance of registration certificate & 1 & 3 & 4 & 5 & 5 & 6 days & 5 days \\
\hline \multirow{4}{*}{ Filing } & 1. Filing of return & 3 & 4 & 4 & 5 & 5 & 3 days & 2 days \\
\hline & 2. Issuance of filing confirmation & 2 & 3 & 4 & 5 & 5 & 6 days & 5 days \\
\hline & 3. Return data entry & 2 & 2 & 3 & 4 & 5 & 6 days & 5 days \\
\hline & 4. Review/verification of return data & 1 & 1 & 2 & 3 & 4 & 30 days & 30 days \\
\hline \multirow{4}{*}{ Payment } & 1. Providing right amount payable & 3 & 4 & 4 & 5 & 5 & 3 days & 2 days \\
\hline & 2. Enable payment of taxes & 3 & 4 & 4 & 5 & 5 & 3 days & 2 days \\
\hline & 3. Processing of payment received & 2 & 3 & 4 & 4 & 5 & 6 days & 5 days \\
\hline & $\begin{array}{l}\text { 4. Processing of } \\
\text { suspended payments }\end{array}$ & 1 & 1 & 2 & 3 & 4 & 31 days & 30 days \\
\hline \multirow{5}{*}{$\begin{array}{l}\text { Revenue } \\
\text { Accounting }\end{array}$} & 1. Posting of taxpayer liabilities & 3 & 4 & 4 & 5 & 5 & 3 days & 2 days \\
\hline & 2. Taxpayer account reconciliation & 2 & 3 & 4 & 4 & 5 & 31 days & 30 days \\
\hline & 3. Issue Tax Clearance Certificate & 2 & 3 & 4 & 5 & 5 & 6 days & 5 days \\
\hline & 4. Revenue reconciliation & 1 & 1 & 2 & 3 & 4 & 31 days & 30 days \\
\hline & 5. Revenue reporting & 1 & 2 & 3 & 4 & 5 & 16 days & 15 days \\
\hline \multirow{5}{*}{ Refunds } & 1. Submission of refund claim & 3 & 4 & 4 & 5 & 5 & 3 days & 2 days \\
\hline & 2. Refund claim data entry & 1 & 2 & 3 & 4 & 5 & 16 days & 15 days \\
\hline & $\begin{array}{l}\text { 3. Refund claim review/verification } \\
\text { and approval }\end{array}$ & 1 & 2 & 3 & 4 & 5 & 16 days & 15 days \\
\hline & $\begin{array}{l}\text { 4. Refund allocation to } \\
\text { outstanding liabilities }\end{array}$ & 1 & 1 & 2 & 3 & 4 & 31 days & 30 days \\
\hline & $\begin{array}{l}\text { 5. Refunding to taxpayer } \\
\text { (by Treasury) }\end{array}$ & 1 & 1 & 2 & 3 & 4 & 31 days & 30 days \\
\hline
\end{tabular}




\section{APPENDIX 2. ELEMENTS OF AN INFORMATION TECHNOLOGY SUPPORT PLAN}

\section{Maintain Essential Support Functions}

Implement enhanced measures that guarantee the secure availability of identified essential support functions. Report planned, anticipated or actual service disruptions to the CMT Leader without delay.

$\checkmark$ Implement crisis action plans for (1) email; (2) connectivity; (3) and data exchange

\section{Confirm Emergency Procedures and Core Operations}

Ensure that approved emergency IT procedures, failover ${ }^{6}$ techniques, and backups for core IT operations are in-place and appropriately configured for crisis conditions in an epidemic scenario. Analyze critical procedures, infrastructure, systems, and support services to ensure their viability in a remote work configuration. Identify single points of failure and initiate emergency procurements.

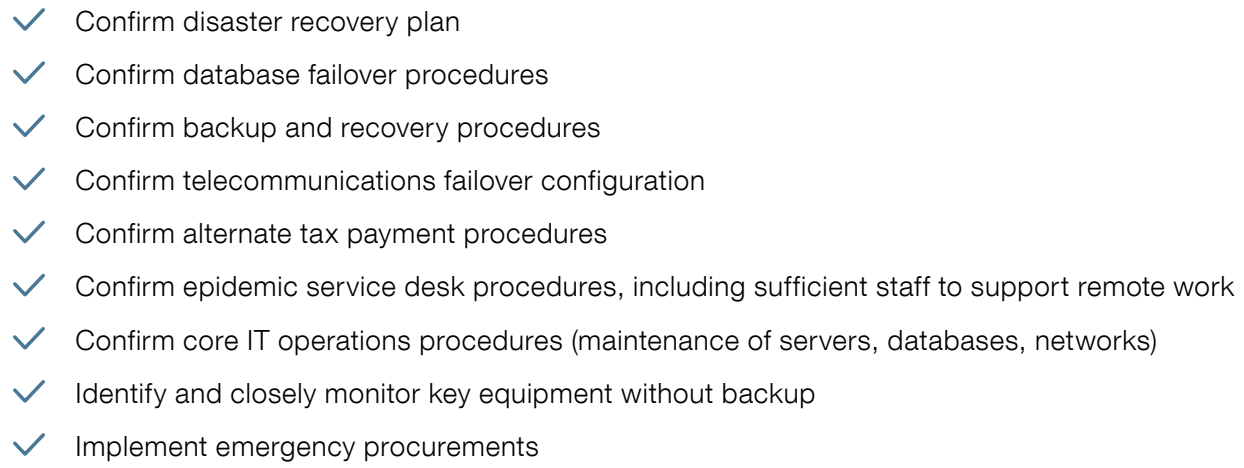

\section{Coordinate with Key Partners}

Manage critical dependencies (i.e., processes, data exchange, IT services) and relationships with partners, including commercial banks, the national bank, Treasury and Customs, suppliers, and service providers.
$\checkmark$ Alert key partners of BCP activation
$\checkmark$ Confirm service provider expectations
$\checkmark$ Confirm data center operations
$\checkmark$ Coordinate partner dialogue

\section{Deploy Remote Work Capabilities}

Lead the deployment of the devices and electronic services required to provide secure workfrom-home capabilities for staff. Regularly report progress to the CMT Team Leader, noting potential obstacles.

$\checkmark$ Confirm back-office management services

$\checkmark$ Confirm information security controls

$\checkmark$ Confirm infrastructure security controls

$\checkmark$ Confirm internal audit systems and tools

\section{CInternational Monetary Fund. Not for Redistribution}




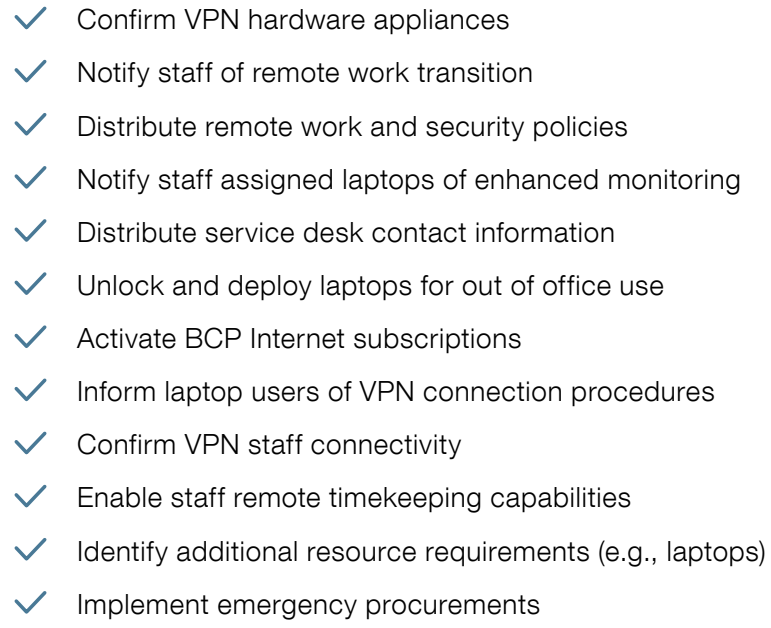

\section{Redeploy IT Staff and Confirm Assignments}

Direct most IT staff to transition into a remote configuration while ensuring that responsibilities for core IT operations are clear. Ensure sufficient resources to support the broader remote workforce transition.

$\checkmark$ Direct non-essential IT staff to work from home

$\checkmark$ Confirm staff assignments for core operations

$\checkmark$ Confirm rotating data center and site visit schedules

$\checkmark$ Coordinate local office IT support personnel

\section{Deliver Priority Systems Development}

Establish a team to implement reengineered business processes and policy measures.

Relax change controls for low-risk interventions. Reconcile BCP action plan requirements with current conditions.

$\checkmark$ Designate a reengineering team leader

$\checkmark$ Determine systems changes based on current conditions

$\checkmark$ Rapidly implement easy, low-risk changes

$\checkmark$ Plan and fully test medium- and high-risk changes

\section{Secure Information and Assets in Closing Facilities}

Manage the shutdown, storage and security of devices and information during the crisis period, accounting for both end-user and back-office assets.

$\checkmark$ Perform a full equipment inventory (i.e., PCs, laptops, etc.)

$\checkmark$ Direct staff to centrally backup files on a server

$\checkmark$ Disable all wireless transmission devices (e.g., WIFI routers)

$\checkmark$ Physically secure devices with sensitive or classified information 


\section{TNM/2020/001}

International Monetary Fund

Fiscal Affairs Department

700 19th Street, NW

Washington, DC 20431 USA

T. +(1) 202.623.8554

F. $+(1) 202.623 .6073$ 